\title{
The prevalence of Diabetic Retinopathy in a Tertiary Centre in Western Region, Nepal
}

\author{
Chandra Bahadur Pun*1i, Sarita Tuladhar ${ }^{2}$, Tirtha Lal Upadhyaya ${ }^{1}$, Jamuna Gurung $^{2}$, Durga Dhungana ${ }^{1}$ \\ I.Department of Medicine, 2.Department of Ophthalmology, Gandaki Medical College and Teaching Hospital, Pokhara, Nepal
}

\begin{abstract}
Background: Diabetes mellitus is a multisystem disease. It has multiple complications like retinopathy, neuropathy, nephropathy, diabetes ketoacidosis, and stroke. Diabetes retinopathy (DR) is one of the blinding complications of diabetes. This study was done to find out the prevalence of diabetic retinopathy among diabetic patients attending in the outpatient department (OPD) of internal medicine, Gandaki Medical College and Teaching Hospital (GMCTHRC), Pokhara, Nepal. Materials and Methods: A hospital based cross-sectional study was performed among the 200 diabetes mellitus patients attending in the medicine OPD from 15th December 2017 to $15^{\text {th }}$ December 2018. They were referred to eye OPD of GMC. The detailed eye examination including fundus evaluation under mydriasis was done to all the patients. The diagnosis of DR was graded using the Early Treatment Diabetic Retinopathy Study classification(ETDRS). Patients having hypertension and other retinal diseases were excluded from the study. Data analysis was done using statistical package for social sciences (SPPS) version 11.20. Results: The mean age of the patients was 63.02 \pm 11.8 years. In our study $60.5 \%$ of the patients were male and $39.5 \%$ were female. Diabetes retinopathy was seen in $29.5 \%$ patients, of which non proliferative diabetes retinopathy (NPDR) was present in $19.5 \%$, proliferative diabetes retinopathy (PDR) in $9.5 \%$ and $0.5 \%$ had diabetes maculopathy. Conclusion: The prevalence of DR is quite significant in the people with diabetes. Early diagnosis and management of retinopathy will help to avoid blindness due to the diabetic retinopathy.
\end{abstract}

Key words: Awareness, Diabetic Retinopathy, Fundus, Prevalence, Tertiary Centre.

\section{Correspondence to:}

Dr. Chandra Bahadur Pun

Associate Professor, Department of Medicine.

Gandaki Medical College and Teaching Hospital,

Pokhara, Nepal.

E-mail: drcbpun98@gmail.com

Submitted: July 27, 2020

Accepted: November 1, 2020

To cite: Pun CB, Tuladhar S, Upadhyaya TL, Gurung J, Dhungana D. The prevalence of Diabetic Retinopathy in a Tertiary Centre in Western Region, Nepal. JGMC Nepal. 2020;13(2):140-3.

DOI: $10.3126 /$ jgmcn.v13i2.30344

\section{INTRODUCTION}

Diabetes Mellitus occurs throughout the world but more common in the more developed countries. In 2019, approximately 463 million adults (20-79 years) were living with diabetes; by 2045 this will rise to 700 million. ${ }^{1}$ Average medical expenditure among people with diabetes are about 2.3 times higher. ${ }^{2}$ Increase in the overall diabetes mellitus prevalence rates largely reflect as incidence in the risk factors.

Diabetes Mellitus is a multisystem disease. Therefore it has multiple complications like retinopathy, neuropathy, nephropathy, diabetes ketoacidosis, and stroke. Diabetes retinopathy is a common complication and responsible for visual impairment and blindness worldwide. ${ }^{3-5}$ According to WHO, it is estimated that DR accounts for $4.8 \%$ of the total number of cases of blindness worldwide. ${ }^{6}$

Diabetic retinopathy occurs due to damage of the microvasculature of the retina as a result of the prolonged exposure to the metabolic changes induced by diabetes. There are different classifications of diabetes retinopathy, but the most widely accepted is ETDRS classification. According to 
this classification, there are three types of DR - NPDR, PDR and diabetes maculopathy. NPDR is associated with microaneurysms, superficial and deep retinal hemorrhages, hard exudates, and macular edema. PDR involves the growth of new blood vessels in the retina that may cause scarification of the retina and vitreous. Maculopathy involves oedema and exudates in macula. Different methods of diagnosing DR clinically include ophthalmoscopy, optical coherence tomography, retinal photography, and fluorescein angiography. ${ }^{7,8}$

Different treatment modalities for DR are- laser, intravitreal avastin, steroids, and vitrectomy. PDR if timely treated can decrease the loss of vision up to $90 \% .{ }^{9}$ Early diagnosis and prompt treatment helps to minimize diabetes-related visual impairment. Patients with diabetes require regular follow-up with physicians to optimize their glycemic, blood pressure and lipid control to prevent development and progression of DR and other diabetes-related complications.

Diabetes and DR is increasing day by day. Nepal is a developing country where knowledge and awareness of diabetes is very poor and not adequate studies have been done regarding its state. Gandaki Medical College (GMC) being a pioneer tertiary centre in Western Nepal, we performed this study to find out the prevalence of diabetic retinopathy.

\section{METHODS}

A hospital based cross sectional study was done from $15^{\text {th }}$ December 2017 to $15^{\text {th }}$ December 2018. A total of 200 patients attending the OPD of medicine of GMC diagnosed as diabetes mellitus were included in the study. They were then referred to the department of ophthalmology. Diagnosis of diabetes was done on the basis of either on use of hypoglycemic agents or according to the American Diabetic Association (ADA) which defines diabetes as having fasting blood sugar level of $126 \mathrm{mg} / \mathrm{dl}$ or higher recording. All diabetic patients having fasting blood sugar level of $126 \mathrm{mg} / \mathrm{dl}$ or higher were included in our study. Ocular evaluation was conducted by a team of ophthalmologists and ophthalmic assistants. Visual acuity was taken by Snellen chart and refraction was done when needed. The anterior segment examination was done using slit lamp. Retina was examined after pupil dilatation with tropicamide eye drop installed three times at interval of ten minutes. Fundus was evaluated with 90 Dioptre and 20 Dioptre aspheric lens. The stages of DR were classified according to the ETDRS classification. All the data were entered and analyzed bySPSS version 11.20

\section{RESULTS}

A total of 200 patients were included in our study. In our study, 60.5\% (121) patients were male while 39.5\% (79) were female. The mean age of the patients was $63.02 \pm 11.8$ years. Details of the different age distribution of the patients are shown in table 1.

\section{Table 1: Age distribution of the patients}

\begin{tabular}{cc}
\hline Age interval in years & No. of patients (\%) \\
$40-49$ & $31(15.5)$ \\
$50-59$ & $40(20)$ \\
$60-69$ & $70(35)$ \\
$70-79$ & $36(18)$ \\
$80-89$ & $20(10)$ \\
$>90$ & $3(1.5)$ \\
Total & $200(100)$ \\
\hline
\end{tabular}

Regarding duration of diabetes, $80.5 \%$ (161) had diabetes for less than 10 years, $12.5 \%$ (25) had diabetes for 11 to 20 years and $07 \%$ (14) had diabetes for 21 to 30 years. Details are shown in table 2.

\section{Table 2: Duration of diabetes and retinopathy}

\begin{tabular}{cc}
\hline Duration (Years) & No of cases (\%) \\
$<10$ years & $161(80.5)$ \\
$11-20$ years & $25(12.5)$ \\
$21-30$ years & $14(7)$ \\
Total & $200(100)$ \\
\hline
\end{tabular}

In our study, diabetes retinopathy was seen in 29.5\% (59) patients of which NPDR was seen in 19.5\% (39), PDR in $9.5 \%$ (19) and maculopathy in $0.5 \%$ (1). Details are shown in table 3.

Table 3: Types of diabetes retinopathy

\begin{tabular}{cc}
\hline Condition & No. of patients $(\%)$ \\
No DR & $141(70.5)$ \\
NPDR & $39(19.5)$ \\
PDR & $19(9.5)$ \\
Maculopathy & $1(0.5)$ \\
Total & $200(100)$ \\
\hline
\end{tabular}

\section{DISUSSION}

Diabetic retinopathy is a medical condition which damages the retina of the eyes due to diabetes mellitus. It is a leading cause of blindness in the developed countries. ${ }^{10,11}$

In our study, $60.5 \%$ (121) patients were male while $39.5 \%$ (79) were female. This is similar to other studies elsewhere.,12-14 In our study, majority of the patients were in sixth decade while other studies showed more patients in fifth decade of life. ${ }^{13,14}$ 
In our study, $80.5 \%$ (161) of the patients had diabetes for less than 10 years which is similar to study done by Shrestha $\mathrm{R}^{14}$ in Nepal, while other studies showed diabetes for more than 10 years. ${ }^{13,15}$

We found $29 \%$ of the patients with DR, which was similar to study done by R Maskey et al. ${ }^{16}$ which showed DR in $27.7 \%$. Meanwhile, a study done by Paudyal $\mathrm{G}$ et al. ${ }^{12}$ showed diabetes retinopathy in $19.4 \%$.Varying prevalence has been seen in different studies in Nepal. High prevalence, upto $78 \%$ was seen in a study by $\mathrm{R}$ Thapa etal. ${ }^{13}, 47.3 \%$ in a study by Rizyal ${ }^{17}$ while a study done by Shrestha $\mathrm{R}^{14}$ showed prevalence of $20.3 \%$. Studies done abroad also showed varying prevalenceof $\mathrm{DR}$, ranging from $15.4 \%$ to $33.9 \%{ }^{18-20}$

In our study, NPDR was seen in $19.5 \%$, PDR in $9.5 \%$ and maculopathy in $0.5 \%$. Other studies done in Nepal also showed varying prevalence of NPDR ranging from $13.28 \%$ to $14.7 \%$, PDR ranging from $7.3 \%$ to $6.9 \%$ and maculopathy in $4.6 \% .^{12,14}$

The higher prevalence of DR in our study may be due to late presentation of the diabetic patients to the hospital and lack of awareness of DR.The difference in the prevalence of DR and different stages of retinopathy in different studies from Nepal and from other parts of the world could have resulted due to the variation in diabetic patients attending these institutes. The prevalence of retinopathy could have been higher in the studies which included participants from the area with poor health facilities or the institutes where referral is more from primary and secondary institutes such as in our study.

\section{CONCLUSION}

The prevalence of DR is quite significant in the people with diabetes. Regular eye examination and follow up regularly with proper management will help to reduce the blindness due to retinopathy.

\section{REFRENCES}

1. Saeedi P, Peterson I, Salpea P, Malanda B, Karuranga S, Nigel Unwin N.Global and regional diabetes prevalence estimates for 2019 and projections for 2030 and 2045: Results from the International Diabetes Federation Diabetes Atlas. Diabetes research and clinical practice. 2019;157:107843. DOI: 10.1016/j.diabres.2019.107843 PMID: 31518657.

2. Association AD. Economic costs of diabetes in the US in 2017. Diabetes care, 2018;41(5):917-28. DOI: $10.2337 /$ dci18-0007

3. Zhang X, Saaddine JB,Chou CF, Cotch MF, Cheng YJ,
GeissLS. Prevalence of diabetic retinopathy in the United States, 2005-2008. JAMA. 2010;304(6):649-65.DOI: 10.1001/jama.2010.1111 PMID: 20699456.

4. Sharew G,Ilako DR, Kimani K, Gelaw Y.Prevalence of diabetic retinopathy in Jimma University Hospital, Southwest Ethiopia. Ethiopian Med J. 2013;51(2):10513. PMID: 24079154.

5. Fong DS, Aiello LP, Ferris FL 3rd, Klein R. Diabetic retinopathy. Diabetes Care. 2004;27(10):2540-53. DOI:10.2337/diacare.27.10.2540

6. Resnikoff S, Pascolini D, Etya'ale D, Kocur I, Pararajasegaram R, PokharelGP. Global data on visual impairment in the year 2002. Bull World Health Organ. 2004; 82(11):844-51. PMID: 15640920. PMCID: PMC2623053.

7. Torok Z, Peto T, Csosz E, Tukacs E, Molnar AM, Berta A.Combined Methods for Diabetic Retinopathy Screening, Using Retina Photographs and Tear Fluid Proteomics Biomarkers. Journal of Diabetes Research. 2015:623619. https://DOI.org/10.1155/2015/623619.

8. Nayak J, Acharya UR, Bhat PS, Shetty N, Lim TC. Automated diagnosis of glaucoma using digital fundus images. Journal of medical systems. 2009;33(5):337346. DOI:10.1007/s10916-008-9195-z.

9. Sundling V, Gulbrandsen P, Jervell J, Straand J, Care of vision and ocular health in diabetic members of a national diabetes organization: a cross-sectional study. BMC health services research. 2008;8(1):159. DOI: $10.1186 / 1472-6963-8-159$

10. Mensah E, Kohner E.Diagnosis and management of diabetic retinopathy. Topic Endocrinol. 2002;19:14-8.

11. Group, U.P.D.S. Tight blood pressure control and risk of macrovascular and microvascular complications in type 2 diabetes. UKPDS38. BMJ. 1998;317(7160):703-13. PMID- 9732337.

12. Paudyal G, Shrestha MK, Poudel M, Tabin GC, Ruit S, Benjamin J, Thomas BJ. Prevalence and severity of diabetic retinopathy among diabetic patients presenting to a tertiary eye hospital in Nepal. Middle East African Journal of Ophthalmology. 2019;26(4):210. DOI: 10.4103/meajo.MEAJ0_65_18

13. Thapa R, PaudyalG, Maharjan N, Bernstein PS. Demographics and awareness of diabetic retinopathy among diabetic patients attending the vitreo-retinal service at a tertiary eye care center in Nepal. Nepalese Journal of Ophthalmology. 2012;4(1):10-6. 
14. Shrestha R. Ocular manifestations in diabetes, a hospital based prospective study. Nepal Med Coll J. 2011;13(4):254-6.

15. Diabetic Retinopathy Clinical Research Network, Wells JA, Glassman AR, Ayala AR, Jampol LM, Aiello LP. Aflibercept, bevacizumab, or ranibizumab for diabetic macular edema. NEJM. 2015;372(13):1193-203. DOI: 10.1056/NEJMoa1414264

16. Maskey R, Shakya DR, Sharma SK, KarkiP, Lavaju P. Diabetes mellitus related complications in out-patient clinic of tertiary care hospital. Journal of College of Medical Sciences-Nepal. 2011;7(2):9-16. DOI:10.3126/ jcmsn.v7i2.6674

17. Rizyal A. Ocular manifestations in diabetes mellitus: an experience at Nepal Medical College Teaching Hospital. NMCJ. 2004;6(2):136. PMID: 16295747.
18. Vaz NC, Ferreira A, Kulkarni M, Vaz FS, Pinto N.Prevalence of diabetic complications in rural Goa, India. Indian journal of community medicine. official publication of Indian Association of Preventive \& Social Medicine. 2011;36(4):283-6. DOI: 10.4103/0970-0218.91330. PMID: 22279258.

19. Ramavat P.R,RamavatMR, Ghugaree B, Vaishnav G, Joshi $M$. Prevalence of Diabetic retinopathy in Western Indian type 2 diabetic population.A hospital-Based crossSectional study. JCDR. 2013;7(7):1387.

20. Rema M,Premkumar S, Anitha B, Deepak R, Pradeepa R, Mohan V. Prevalence of diabetic retinopathy in urban India: the Chennai Urban Rural Epidemiology Study (CURES) eye study. Investigative ophthalmology \& visual science. 2005;46(7):2328-33. DOI:https://doi. org/10.1167/iovs.05-0019 